\title{
The Osteomyocutaneous Free Fibula Flap in Mandibular Reconstruction
}

\author{
Hyder Ali ${ }^{1}$, Sufyan Ahmed ${ }^{2 *}$, Noor ul Wahab ${ }^{3}$, Huzaifa Saeed ul Khair ${ }^{3}$ and Muhammad Ashraf Ganatra ${ }^{4}$ \\ ${ }^{1}$ Department of Plastic \& Reconstructive Surgery, Dow University of Health Sciences \& Civil Hospital Karachi, Pakistan \\ ${ }^{2}$ Department of Oral \& Maxillofacial Surgery, Karachi Medical \& Dental College, Pakistan \\ ${ }^{3}$ Department of Oral and Maxillofacial Surgery, Ziauddin College of Dentistry, Pakistan \\ ${ }^{4}$ Department of Plastic \&Reconstructive Surgery, Dow University of Health Sciences \& Civil Hospital Pakistan \\ Received: April 24, 2018; Published: May 14, 2018 \\ *Corresponding author: Sufyan Ahmed, Department of Oral and Maxillofacial Surgery, Karachi Medical \& Dental college, Pakistan
}

\section{Abstract}

Introduction: Functional reconstruction of mandible is one of the most challenging problems in maxillofacial reconstruction in ablative defects especially after tumour surgery, with the problem becoming complicated after cases of composite tissue resection. Many composite flaps based on microvascular free tissue transfer are now used for functional reconstruction with varying success.

Objectives: To determine the function, cosmesis, and complications of the free fibular flap along with morbidity of the donor site.

Study Design: A descriptive clinical experimental study.

Setting: Department of Plastic \& Reconstructive Surgery, Dow University of Health Sciences \& Dr Ruth K.M. Pfau Civil Hospital Karachi, Pakistan.

Duration: From January 2015 to December 2017.

Subjects: 15 patients.

Methods: Data was collected through a specially designed preformed, which included a complete history, clinical examination, laboratory investigations and imaging, preoperative findings and postoperative results, complications and follow-up findings. Data was analyzed through SPSS version 21.0.

Results: In this study there were 11 male patients while 4 patients were females. Average age was 46 years (range 23-65 years). In $90 \%$ of patients the tumour was Squamous cell carcinoma. "L" segment of mandible was excised in 63\%, "C" segment in $20 \%$ and "H" segment in $17 \%$. Range of mandibular defect was $7-25 \mathrm{~cm}$. Only 2 patients had total flap failure, 2 had partial flap failure, plate exposure/extrusion was seen in 1 patient, and major Orocutaneous fistula and donor site dehiscence was noted in 1 patient. Donor site morbidity was low. Restoration of mandibular contour was acceptable in $53.3 \%$ patients. $40 \%$ of the patients were able to consume normal diet and $53 \%$ of patients were on soft or blended diet. 9 (60\%) patients had intelligible sound. Aesthetic result of the flap was good in $50 \%$ of the patients, excellent in $23 \%$ and fair in $26 \%$ of cases.

Conclusion: Osteocutaneous free fibula flap for reconstruction of mandibular defect is a good choice in terms of function, cosmesis, less complications and acceptable donor site morbidity.

Keywords: Osteocutaneous flap; Free flap; Mandibular reconstruction; Oral squamous cell Carcinoma; Free fibular flap Abbreviations: FFF: Free Fibular Flap; O: Oral; SCC: Squamous Cell Carcinoma 


\section{Introduction}

Reconstruction of the mandibular defects after tumour resection or trauma is one of the most challenging problems facing reconstructive surgery. The major role played by the mandible in airway protection and support of the tongue, lower dentition, and mastication, articulation, and deglutition. It also contributes to airway stability; and determines the shape and contour of the lower face. Interruption of mandibular continuity therefore, produces both a cosmetic and debilitating functional deformity. Functional and aesthetic considerations hence become the inherent objectives when considering mandibular reconstruction [1]. The vast majority of segmental mandible defects are caused by head and neck cancer of which Squamous cell carcinoma (SCC) and estrogenic sarcoma is the most common [2]. Resection of established SCC involving the mandible usually includes wide excision of intra-oral mucosa, bone and external skin. Because of the complexity of these composite defects, free fibula osteocutaneous flap is regarded as a good choice for reconstruction [3].

A high incidence of OSCC is seen in Pakistani population, with the most affected patients being in 4th - 6th decades of their life [4]. Data of Karachi Cancer Registry shows oral cancers to be the second most common malignancy in males and in females. Annual incidence is seen to be 4.1/100,000 in males and 4.0/100,000 in females [5]. Alveolar mucosa of the mandible is frequently involved followed by buccal mucosa (46.6\%), with a radiographic evidence of bony erosion in $43 \%$ of cases [6]. The reconstruction of mandible was done by using non-vascularized free bone graft, cancellers bone packed into stainless steel or vitally trays, and pectorals major with attached rib grafts [7] Taylor et al described free vascularized fibula $[8,9]$ which was popularized in [10]. A significant series of Urkan introduced the sensate free flap for head and neck reconstruction [11].

In comparison with other osteocutaneous flaps it has several advantages in mandibular reconstruction. A good bone length can be harvested, with a consistent bone shape, adequate bone height, and segmental blood supply and flexible skin island [12] which is seen to be reliable in $91 \%$ of patients [13] and osteotomies can be placed as close as $1 \mathrm{~cm}$ apart without concern for bone viability. For these multiple reasons, FFF has become one of the most important resources in head and neck reconstructive surgery with a number of significant advantages over other osteocutaneous donor sites [14] Earlier reports from Pakistan on its use have shown it to be a choice par excellence for oromandibular defects [15].

\section{Materials and Methods}

The objectives of this study are to assess the functional rehabilitation in terms of speech, deglutition and mastication and to assess the cosmetic reconstruction of mandible in terms of contour and symmetry during static and dynamic movement. This descriptive prospective study was conducted at the Department of Plastic \& Reconstructive Surgery, Dow University of Health
Sciences \& Dr Ruth KM Pfau Civil Hospital Karachi, Pakistan, from January 2015 to December 2017 and includes 15 patients with non- probability, convenient sampling technique. All patients with partial, total or composite resection of mandible due to head and neck tumours, requiring primary bony reconstruction with FFF were included. Those patients who presented for a secondary reconstruction after a failed primary reconstruction were excluded from the study. Data was collected through a specially designed preformed, after the patient fulfilling the inclusion criteria of the study. Patient's history including personal and family history was recorded, clinical examination (local examination of the lesion, examination of neck and systemic examination), investigations including (Complete blood count, Chest x-ray, OPG, CT scan / MRI), and histopathology for TNM staging of the tumour, preoperative findings and donor site closure with or without skin graft. Complications were assessed in terms of flap survival, wound dehiscence and plate extrusion. Patients were followed up for 1 week, 2 weeks and 4 weeks postoperatively. Final outcome was measured in terms of flap survival, pain, aesthetics, and function. Data was analyzed by using SPSS version- 21 .

\section{Surgical Approach}

After the patient deemed fit to undergo a lengthy procedure through the pre-anesthetic assessment and also when in the case of malignant disease the primary and neck sites were considered operable, the regular preoperative protocol consisting of usual general anesthesia preparation was done. The lateral side of the leg was assessed with Doppler ultrasonography for identification of skin perforators. The perforators were then marked over the skin and the flap was designed to incorporate at least one skin perforator in the skin flap. Inter-muscular septum was palpated which was used as an important landmark. Four centimeters of bone was preserved on the proximal side to avoid injury to common peroneal nerve while six centimeters of bone was preserved distally to maintain the ankle mortise. The size of the skin paddle was designed slightly bigger than the expected defect. The skin incision was made around the skin paddle with distal and proximal extensions that allow for vascular pedicle dissection and bone harvest. Fibular bone can be visualized by reflecting peroneus long us anteriorly and posterior crural septum is identified. Mono polar cautery system must not be used for dissection to circumvent injury to fragile skin perforators. After transecting the extensor halluces long us and identification of thick interosseous septum, anterior dissection of the fibula was completed. Dissection from the posterior aspect was done after freeing the skin paddle from gastronomies and soleus muscle and identifying the septum from the posterior aspect. An oscillating saw was used to make the bony cuts and bone retractors were used to pull the bone laterally.

Bipolar cautery was used to transect the V-shaped tibialis posterior and the pedicle lies just below this muscle. The pedicle was identified and legated distally. After transecting the soleus and flexor halluces long us muscles, dissection was carried proximally up 
to the bifurcation posterior tibial vessels. Pulses from the posterior and anterior tibial vessels must be palpated before dividing the peroneal vessels. After measuring the required amount of bone for reconstruction, proximal elevation of the periosteal along the fibular bone permits sizing of the bone and extending of the vascular pedicle. Osteotomies were done if bone contouring is required. Some surgeons prefer to divide the vascular pedicle and perform osteotomies on a back table while others perform osteotomies while the flap is still vascularized in the leg. Primary closure of the leg wound is usually attempted or else a split thickness skin graft may be used. A posterior leg splint was also placed. After plating the fibular bone, it was placed into defect. The vascular pedicle was kept on the lingual side of the flap and skin paddle was inserted and secured with horizontal mattress sutures. Standard micro-vascular techniques were utilized to perform the anastomosis of the vessels. Suction drains must be placed with care in the neck.

\section{Results}

15 patients underwent FFF reconstruction with the mean age of the patients being 47 years (23-65 years). Male: female ratio2.33:1. Histopathology reports showed 13 patients with malignant tumours while benign tumours were in only 2 patients. Lateral part of the mandible (L) was involved in 10cases, central part (C) in 3 cases and hemi mandible $(\mathrm{H})$ in 2 cases. Mandibular defect was $<7 \mathrm{~cm}$ in $30 \%, 8-14 \mathrm{~cm}$ in $56.7 \%$ and $>14 \mathrm{~cm}$ in $13.3 \%$ of cases. Soft tissue used for both the covering and lining was in $12(76.6 \%)$ cases while only $3(23.3 \%)$ cases need soft tissue for mucosal lining. Skin paddle ranged from $6 \times 5 \mathrm{~cm}$ to $16 \times 10 \mathrm{~cm}$. (Table 1) Donor site morbidity after harvesting of the fibula was assessed by a point evaluation system [16]. Skin grafting was done in all the cases and the patients experienced mild pain in donor leg in 11 cases and intermediate to moderate pain in 4 cases. No major limitation during walking was observed, minor were experienced in 3 patients, and 12 patients experienced intermediate limitations. There was no major restriction in the activities of the patients; only minor disability was experienced in $70 \%$ of the patients. Most of the patients were satisfied with the donor site cosmesis (Table 2). There was total failure of flap in 2 cases and partial flap necrosis in 2 cases. Orocutaneous fistula was found in 1 case, dehiscence of donor site in 1 case and exposure of reconstruction plate in 1 case.

Table 1: Demographic Data and Defect Classification.

\begin{tabular}{|c|c|c|c|c|c|}
\hline S.No & Age/Gender/ side & pathology & $\begin{array}{l}\text { Mandibular Defect } \\
(\mathrm{cm})\end{array}$ & $\begin{array}{l}\text { Classification (sm=skin \& mucosa, } \\
\text { m=mucosa) }\end{array}$ & Skin Paddle (cm) \\
\hline 1. & $50 / \mathrm{F} / \mathrm{L}$ & SCC & 8 & $\mathrm{~L}, \mathrm{sm}$ & $16 \times 8$ \\
\hline 2. & 48/M/L & SCC & 9 & $\mathrm{~L}, \mathrm{sm}$ & $12 \times 8$ \\
\hline 3. & $55 / \mathrm{M} / \mathrm{L}$ & SCC & 10 & $\mathrm{~L}, \mathrm{sm}$ & $16 \times 10$ \\
\hline 4. & $32 / \mathrm{M} / \mathrm{L}$ & SCC & 8 & $\mathrm{~L}, \mathrm{sm}$ & $10 \times 8$ \\
\hline 5. & $52 / \mathrm{M} / \mathrm{L}$ & SCC & 11 & $\mathrm{H}, \mathrm{sm}$ & $8 \times 4$ \\
\hline 6. & $60 / \mathrm{M} / \mathrm{R}$ & SCC & 8 & $\mathrm{~L}, \mathrm{sm}$ & $12 \times 6$ \\
\hline 7. & $50 / \mathrm{M} / \mathrm{L}$ & SCC & 8 & $\mathrm{~L}, \mathrm{sm}$ & $8 \times 4$ \\
\hline 8. & $32 / \mathrm{F} / \mathrm{R}$ & SCC & 11 & $\mathrm{~L}, \mathrm{~m}$ & $8 \times 6$ \\
\hline 9. & $23 / \mathrm{F} / \mathrm{L}$ & Giant cell granuloma & 7 & $\mathrm{~L}, \mathrm{~m}$ & $10 \times 5$ \\
\hline 10. & 48/M/L & SCC & 10 & $\mathrm{~L}, \mathrm{sm}$ & $8 \times 6$ \\
\hline 11. & $50 / \mathrm{F} / \mathrm{L}$ & Ameloblastoma & 10 & $\mathrm{~L}, \mathrm{~m}$ & $10 \times 7$ \\
\hline 12. & $24 / \mathrm{F} / \mathrm{L}$ & SCC & 25 & $\mathrm{H}, \mathrm{m}$ & $7 \times 4$ \\
\hline 13. & 48/M/L & SCC & 7 & $\mathrm{~L}, \mathrm{sm}$ & $6 \times 5$ \\
\hline 14. & $55 / \mathrm{M} / \mathrm{R}$ & SCC & 8 & $\mathrm{C}, \mathrm{m}$ & $8 \times 6$ \\
\hline 15. & $60 / \mathrm{M} / \mathrm{R}$ & SCC & 7 & $\mathrm{C}, \mathrm{sm}$ & $12 \times 8$ \\
\hline
\end{tabular}

Table 2: Surgical Outcome \& Donor-Site Morbidity.

\begin{tabular}{|c|c|c|c|c|}
\hline \multirow[t]{2}{*}{ S. No } & \multicolumn{3}{|c|}{ Surgical Outcome } & \multirow[t]{2}{*}{ Morbidity } \\
\hline & Deglutition & Speech & Contour & \\
\hline 1. & Regular & Intelligible & Acceptable & Low \\
\hline 2. & Regular & Intelligible & Satisfactory & Low \\
\hline 3. & Soft & Intelligible with concentration & Satisfactory & Intermediate \\
\hline 4. & Regular & Intelligible & Satisfactory & Intermediate \\
\hline 5. & Soft & Intelligible with concentration & Acceptable & Low \\
\hline 6. & Regular & Intelligible & Acceptable & Low \\
\hline 7. & Regular & Intelligible & Acceptable & Low \\
\hline
\end{tabular}




\begin{tabular}{|c|c|c|c|c|}
\hline 8. & Soft & Intelligible with concentration & Unsatisfactory & Intermediate \\
\hline 9. & Soft & Intelligible with concentration & Acceptable & Low \\
\hline 10. & Regular & Intelligible & Acceptable & Low \\
\hline 11. & Soft & Intelligible with concentration & Satisfactory & Acceptable \\
\hline 12. & Regular & Intelligible & Satisfactory & Low \\
\hline 13. & Regular & Intelligible & Satisfactory & Low \\
\hline 14. & Regular & Intelligible & Unsatisfactory & Intermediate \\
\hline 15. & Feeding tube & Unintelligible & & \\
\hline
\end{tabular}

Evaluate the postoperative results was done in terms of restoration of mandibular contour, deglutition and speech [17]. Acceptable mandibular contour after reconstruction was observed in 8 patients, 5 patients had satisfactory results and 2patients were unsatisfied. In our series 9 patients could masticate the normal food, while 5 patients could easily tolerate the soft or blended diet and only 1 patient were kept on prolonged nasogastric tube feedings. Intelligible speech was found in 9 patients and intelligible with concentration in 4 patients and 2 patients had unintelligible sounds. Nearly half of the patients were satisfied regarding the aesthetic outcome of the flap, fair results were seen in 4 cases while 4 patients were scored as excellent. No patient complained regarding the poor cosmetic appearance of the flap (Table 3).

Table 3: Complications and Aesthetic results of the Procedure.

\begin{tabular}{|c|c|c|}
\hline S. No & Complications & Aesthetics \\
\hline 1. & Nil & Excellent \\
\hline 2. & Nil & Good \\
\hline 3. & Partial necrosis & Good \\
\hline 4. & Orocutaneous fistula & Good \\
\hline 5. & Nil & Fair \\
\hline 6. & Nil & Good \\
\hline 7. & Donor site dehiscence & Fair \\
\hline 8. & Failed & Fair \\
\hline 9. & Nil & Fair \\
\hline 10. & Nil & Good \\
\hline 11. & Nil & Excellent \\
\hline 12. & Nil & Excellent \\
\hline 13. & Partial necrosis & Gxcellent \\
\hline 14. & Nil & Good \\
\hline 15. & Failed & \\
\hline
\end{tabular}

\section{Discussion}

Advances in reconstructive technique, with the use of free microvascular flaps have enabled surgeons to allow large en-bloc resections with complex one stage reconstruction [18]. Despite the refinements of microvascular techniques the exact nature of effects of pre-existing medical conditions and radiotherapy on small vessel pathology has not yet been fully elucidated [19-21]. Our study supports the previously published local data in which $70 \%$ of the patients presenting with oral cancer in which the mandible was excised along with the tumour belonging to an age group of
40- 60 years. Males were commonly affected by oral cancers than females (2.3: 1), as compared to a study showed the male: female was 2.7: 1 . Another study showed the ratio of 1.7: 1 [13]. Oral cavity is the commonest site affected among head and neck cancers [22]. SCC comprises more than $90 \%$ of oral cavity malignant tumours. In our study it also accounted for $90 \%$ of the total cases. In our setup most of the affected patients used betel leaf, betel nut or consumed tobacco in the form of smoked cigarettes. In the western literature, the increase in oral cancers has been documented due to the use of smoking and alcohol, which is not a major contributing factor for our population [22].

Good surgical exposure is necessary for adequate resection of the tumor and achieving tumor free margins is the primary goal in ablative surgery $[23,24]$. A histological assessment through frozen sections of the marrow scrapings and contents of the inferior alveolar canal was done to confirm the clearance of margins in case of doubtful margins [25]. Only 4 patient had mucosal defects with resection of mandible that were amenable to primary closure and the majority of the $(76.6 \%)$ patients needed soft tissue coverage for mucosal lining reconstruction and skin coverage, as compared with a study in which $65 \%$ of patients needed external skin coverage and mucosal lining reconstruction for through and through defects [26].

Initially bone grafts [27,28] and all plastic implants [29] were used to reconstruct mandibular defects followed by the era of pedicle flaps with incorporated bony components which provided very good and reliable soft tissue but were plagued by poorly vascularized bone which led to excessive bone resorption and extrusion especially following radiotherapy. With the advent of microsurgery the options expanded to a great variety. Various free vascularized flaps (scapula, ileum, fibula and radial forearm) can be used to reconstruct the post composite resection defects for oromandibular cancers. Use of a combination of two free flaps is also an established option of reconstruction for large and complex defects [30]. Each flap has its own advantages and disadvantages. We use free fibular osteocutaneous flaps due to its obvious merits in meeting the functional and aesthetic goals for mandibular reconstruction [31]. In our series total flap failure was $10 \%$ and necrosis of superficial skin paddle was found in $10 \%$ of cases. These complications were $14.7 \%$ and $5.9 \%$ in other published series, respectively. Major Orocutaneous fistula was found in 3.3\% of cases which was $5.8 \%$ in other series [17]. 
A large sized skin paddle is also very predictably raised with the use of FFF and a low percentage (10\%) of skin necrosis is evidence to that with the fact that other factors at the micro circulatory level might also be important in the development of a partial necrosis of the skin paddle. Osteotomies were done in most cases with the use of the respected mandible to form the proper contour and shape of the transplanted tissue. We found that $2.0 \mathrm{~mm}$ manipulates with monocortical screws applied in the same fashion as for mandibular fractures help to minimize periosteal detachment from the transplanted bone. The patients' perception of donor-site morbidity after fibular harvesting was low, relative to total score of each patient, which is also comparable to other studies16. In our series $76.7 \%$ of the patients showed low morbidity after partial resection of fibula and $23.3 \%$ showed intermediate morbidity. This figure was $50 \%$ and $10 \%$ respectively in another published series, that study also concluded the major morbidity in $10 \%$ of cases and no morbidity in $30 \%$ of cases. The cosmetic appearance of donor site was good in most of the cases comparable with other studies. Majority of the patients in our series can perform near normal daily routine activities. They have intelligible speech and good mandibular contour after reconstruction with fibula, and can take regular diet.

\section{Conclusion}

Mandibular defects continue to be difficult challenge for plastic surgeon. The free fibular flap exemplifies the mainstay of mandibular reconstruction at majority institutes which permits the transfer of soft tissue and bone with estrogenic potential and a prolific vascular supply; therefore, the effects of postoperative radiotherapy are well tolerated, and the newly reconstructed mandible can perform an active part in osteosynthesis. Careful selection of osteocutaneous free-flap donor sites for these reconstructions allows the optimal restoration of both function and cosmesis.

\section{Acknowledgement}

The authors would like to thanks The Department of Plastic \& Reconstructive Surgery at Dow University of Health Sciences \& Dr. Ruth K.M. Pfau Civil Hospital, Karachi, The Department of Oral \& Maxillofacial Surgery at Ziauddin University Hospital, Karachi \& The Department of Oral \& Maxillofacial Surgery Karachi Medical \& Dental College \& Abbasi Shaheed Hospital, Karachi, for their general support.

\section{References}

1. Disa JJ, Matros E (2014) Mandible Reconstruction. In: Grab's and Smith's Plastic Surgery. Philadelphia: Lippincott Williams \& Wilkins Publishers 410-419.

2. Stavrianos SD, McLeanNJ, Fellows S, Hodgkinson PD, Kastuki A, et al (2003) Microvascular histopathology in head and neck oncology. Br J Plast Surg 56(2): 140-144.

3. Jones NF, Vogelin E, Markowitz BL, Watson JP (2003) Reconstruction of composite through and through mandibular defects with a double skin paddle fibular osteocutaneous flap. Plast Reconstr Surg 112(3): 758765.
4. Mubashir A, Aftab HB, Tariq M, Shamim AK, Ghulam S, et al. (1998) An epidemiological study of 202 cases of oral cavity cancer (OCC) in Pakistani subjects. Biomedica 14: 27-31.

5. Bhurgri Y, Rahim A, Bhutto K, Bhurgri A, Pinjani P, et al. (1998) Incidence of carcinoma of the oral cavity in Karachi-district south. J Pak Med Assoc 48(11): 321-325.

6. Massod AZ, Masroor UA, Farhat J (2002) A profile of oral cancer presenting at ASH. Ann Abbasi Shaheed Hosp Karachi Med Dent Coll 7: 350-353.

7. Conley J (1972) Use of composite flaps containing bone for major repairs in the head and neck. Plast Reconst Surg 49(5): 522-526.

8. Taylor GI, Miller GDH, Ham FJ (1975) The free vascularized bone graft. A clinical extension of Microvascular techniques. Plast Reconstr Surg 55(5): 533-544.

9. Pacifico MP, Floyd D, Wood SH (2003) Tibial stress fracture as a complication of free fibula vascularized graft for mandible reconstruction. Br J Plast Surg 56(8): 832-834.

10. Hidalgo DA (1989) Fibular free flap: a new method of mandible reconstruction. Plast Reconstr Surg 84(1): 71-79.

11. Urkan ML, Weinberg H, Vickery C, Buchbinder D, Lawson W, et al. (1991) The internal oblique-iliac crest free flap in compositor defects of the oral cavity involving bone, skin and mucosa. Laryngoscope 101(3): 257-270.

12. Hidalgo DA, Rekow A (1995) A reviews of 60 consecutive fibula free flap mandible reconstruction. Plast Reconstr Surg 96(3): 585-596.

13. Rashid M, Ahmad T, Ansari TN, Ahmed B, Ahmed S, et al. (2004) Management of oromandibular cancers. J Coll Physicians Surg Pak 14(1): 29-34.

14. Mantooth GA, Wagner JD (2000) Free fibula flap. In: Auchaur BM, Erikson E, Guyuron B, Coleman JJ III, Russell RC, Kolk CAV, (Eds). Plastic surgery indications operations and outcomes. Missouri: Mosby 1279-1287.

15. Wei FC, Sean CS, Tsai YC, Liu SJ, Tsai M (1994) Fibular osteocutaneous flap for reconstruction of composite mandibular defects. Plast Reconst Surg 93: 294-304.

16. Bodde EWH, de Visser E, Duysens JEJ, Hartman Ed HM (2003) Donor-site morbidity after free vascularized autogenous fibular transfer: Subjective and quantitative analysis. Plast Reconstr Surg 111(7): 2237-2242.

17. Takushima A, Harii K, Ataso H, Nakatsuka T, Kimata Y (2001) Mandibular reconstruction using Microvascular free flaps: A statistical analysis of 178 cases. Plast Reconstr Surg 108(6): 1555-1563.

18. Stravinos SD, McLean NR, Fellows S, Hodgkinson PD, Kostaki A (2003) et al. Microvascular histopathology in head and neck oncology. Br J Plast Surg 56(2): 140-144.

19. Simpson KH, Murphy PG, Hopkins PM, Batchelor AG (1996) Prediction of outcomes in 150 patients having micro vascular free tissue transfer to the head and neck. Br J Plast Surg 49: 267-73.

20. Van Gelder PA, Klopper PJ (1981) Microvascular surgery and diseased recipient vessels. Surgery 90: 860-867.

21. Shibahara T, Schmelzeisen H, Noma H (1996) Histological changes in vessels used for Microvascular reconstruction in the head and neck. J Craniomaxillofac Surg 24(1): 24-28.

22. DeLacure MD, Kuriakose MA (2000) The oral cavity. In: Auchauer BM, Erikson E, Guyuron B, Coleman JJ III, Russell RC, Kolk cav. (Eds). Plastic surgery; indications, operations, and outcomes. Missouri: Mosby 12111228.

23. Carlson GW (2000) Oncology and reconstructive principles. In: Auchauer BM, Erikson E, Guyuron B, Coleman JJ III, Russell RC, Kolk CAV, (Eds). 
Plastic surgery; indications, operations, and outcomes. Missouri: Mosby 1067-1092.

24. Netscher DT, Meade RA, Goodman CM, Alford EL, Stewart MG (2000) Quality of life and disease specific functional status following Microvascular reconstruction for advanced (T3 and T4) oropharyneal cancers. Plast Reconst Surg 105(5): 1628-1634.

25. DeLacure MD (1996) Special considerations in the management of mandibles for cancers of the oral cavity. Otolaryngology Head Neck Surg 4: 98-105.

26. Hidalgo DA, Pusic AL (2002) Free flap mandibular reconstruction: A 10year follow-up study. Plast Reconstr Surg 110(2): 438-451.

27. Millard DR, Dembrow V, Shocket E, Zevertnik J, Clinton-Thomas C (1967) Immediate reconstruction of the respected mandibular arch. Am J Surg 114: 605-613.
28. Kazanjian VH (1952) Bone transplanting to the mandible. Am J Surg pp. 633.

29. Freeman BS (1948) The use of vitallium plates to maintain function following resection of the mandible. Plast Reconst Surg 3: 73.

30. Wei FC, Seah CS, Tsai YC, Liu SJ Tsi MS (1994) Fibula osteoseptocutaneous flap for reconstruction of composite mandibular defects. Plast Reconst Surg 93(2): 294-304.

31. Jones NF, Monstrey S, Gambier BA (1996) Reliability of the fibular Osteocutaneous flap for mandibular reconstruction: anatomical and surgical confirmation. Plast Reconst Surg 97(4): 707-716.
To Submit Your Article Click Here:

This work is licensed under Creative Commons Attribution 4.0 License

DOI: $10.32474 /$ IPDOAJ.2018.01.000119

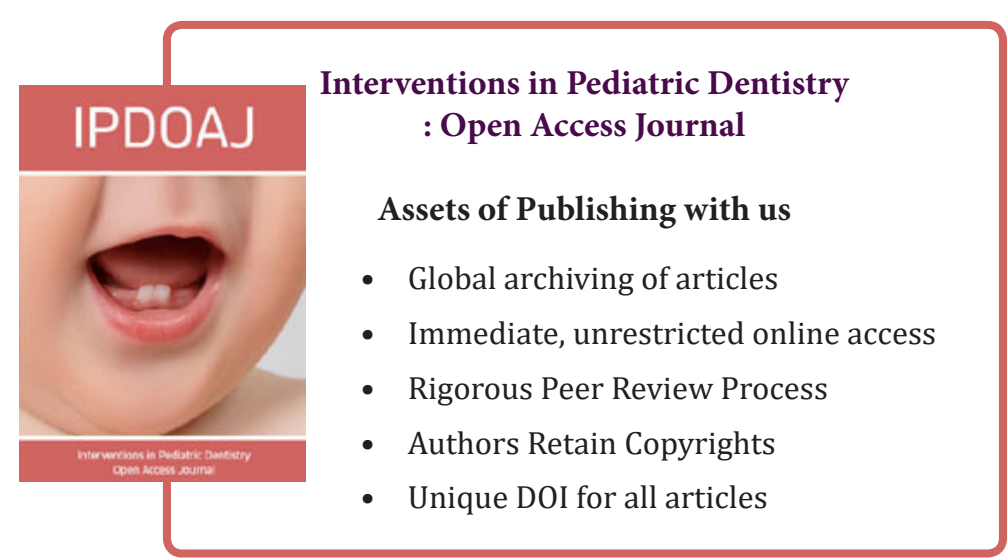

